\title{
A conceptual model of Corporate Social Responsibility, Job Satisfaction, and Organizational Commitment
}

\author{
Ankita Singh, Research Scholar, Management, Dr. APJ Abdul Kalam Technical University, \\ Lucknow, India, ankitasinghndls@gmail.com \\ Dr. N. Lakshmi, Associate Professor, Management, Galgotias College of Engg. \&Technology, \\ Greater Noida, India, nirup.lakshmi@gmail.com
}

\begin{abstract}
Employees are vital stakeholders in a company's day-to-day business, and one of its valuable assets. Concerning Corporate Social Responsibility, employees' perspectives and attitudes are even more important. Most investigations see organizational commitment as a consequence of the social exchange among an organization and the workforce. Corporate Social Responsibility alludes to social duties that organizations have toward stakeholders' group during the section of directing routine business. We contend, based on social exchange and social identity points of view, that Corporate Social Responsibility exercises will impact the dedication of workers and this connection will be encouraged by representative employment fulfillment. Doable inductions of this model have been recognized. Other than offering an extension for additional exploration in the zone of the Indian pharmaceutical industry in conditions, for example, worldwide pandemic COVID-19, it is critical to cultivating submitted representatives as a wellspring of a continued upper hand.
\end{abstract}

Keywords: Corporate Social Responsibility, Employee Job Satisfaction, Organizational Commitment, Social Exchange, Social Identity

\section{INTRODUCTION}

Corporate Social Responsibility (CSR) has been a piece of enthusiasm among scientists starting with the original works of Carroll [17]. The most recent 15 years have seen developing several associations concentrating on CSR activities for various reasons like satisfying social commitments and money related advantages. Organizations are feeling the squeeze from assorted partner gatherings to create separated items, hold the cost structure, and eventually keep up net revenues. Obviously for an organization to cut costs, the info costs should be defended, which works in opposition to the target of creating separated items. Such a situation moves an organization's capacity to be socially capable and give items and administrations at a moderate sum at a comparable time. In this unique circumstance, it seems intriguing to comprehend the perspectives and practices of employees who see their organizations be socially capable. We recommend that if representatives' trust that their organization is socially capable, they are bound to be focused on their organization. Job Satisfaction has additionally been cited as among the most powerful indicators of turnover purpose [14] [34]. Job satisfaction is additionally expected to be a connection to organizational commitment [45] [53]. At long last, contemplates have determined that both organizational commitment and Job satisfaction are impacted by the atmosphere pervasive in the organization [35] [53] [59]. Worker impression of the organization's Corporate Social Responsibility (CSR) activities is to be relied upon to affect their evaluation of the organizational climate [25] [71]. The connection between the ethical climate in an organization, job satisfaction, and organizational commitment has been checked in existing writing [80]. In any case, moral viewpoints structure just one bit of the by and large acknowledged CSR model [17]. Notwithstanding moral duty, CSR joins monetary, lawful, and optional obligations. It is past the extent of this paper to explain the different perspectives on the conceptualization of CSR. In any case, for the judgments of this paper CSR is comprehended as " "perceived socially responsible behavior " of the organization.

Human capital gives an establishment of the continued upper hand. Organizational performance depends, somewhat, on the capacity of the organization to hold and inspire its best workers [9]. When workers see that they have been dealt with similarly by the association they create duty toward the association [20]. Present writing recommends that committed employees are more averse to leave the organization [53]. Meta-scientific examinations have built up various organizationally valuable results of duty like lesser turnover, lesser turnover expectations, and lesser absenteeism [10] [53]. Henceforth, organizational commitment transforms into a significant zone of research 
in organizational conduct. However, there are hardly any investigations into the procedures of the basic development of organizational commitment [53].

Perceived organizational support, (POS) [2], transformational leadership [30], strengthening [74], and trust [4] [55] are a few factors concentrated in blend with equity recognitions and duty. Consequently, there is by all accounts copious writing to propose a positive connection between the view of sensible conduct toward oneself and organizational commitment. In any case, through this theoretical paper, we bolster that more prominent pledge to the organization can grow in any event, when employees see that the organization is reasonable and socially capable of different gatherings. Organizational commitment a strong indicator of 'pure turnover intention' clarifying as much as $51 \%$ fluctuation in turnover intent [53].

Boyacigiller and Adler have called for culture explicit research to be led [15]. Writing has indicated that national culture may impact employees' propensity to confide in their administration [26] [46]. Also, worker business relationships in collectivistic societies demonstrate more likeness to parent-child connections [27]. Thoughts of CSR in India change from those in the West. CSR rehearses in India are bound to a fixation on the representatives, their families, and the general public in a specific order. Along these lines, all things considered, in a collectivistic culture like India the association between the view of socially responsible conduct and organizational commitment would work to some degree uniquely in contrast to from individualistic societies [38].

At last, there are not many examinations that have reviewed the connection between perceived socially responsible conduct and employee commitment through the hypothetical focal points of social exchange and social identity. We suggest that representatives who see the association be socially mindful will be increasingly dedicated and this relationship will be encouraged by job satisfaction.

\section{THEORETICAL FUNDAMENTALS}

Social exchange and social identity theory give the hypothetical premise to this investigation. The social exchange hypothesis gives the calculated cornerstones to the majority of the work on worker conduct and mentality [85] [86]. The social exchange hypothesis depends on the establishment that all connections are on a very basic level social, predicated on trust, and correspondence. Social trade characterized as "the willful activities of people that are propelled by the profits they are required to bring"[13]. Be that as it may, in contrast to financial trade, social trade connections don't work through legally determined commitments. Social exchange among the organization and an employee might be started through strong management practices and fair-minded treatment of the workers [4]. People's grade to respond to favors got from different gatherings, alluded to as the standard of correspondence. Thus, employees' pledge to the organization is frequently seen as the equal activity of people who have gotten support from the organization. Be that as it may, the degree of duty may fluctuate across workers [28]. Existing writing proposes that a solid exchange relationship between the organization and its employees is generally started by the valuable activity of the association or its specialists [23] [31] [64]. Hence, positive activities of the organization produce commitments for employees to respond [29] [70]. On similar lines, writing recommends that unprompted agreed hierarchical activity prompts positive worker businessrelated mentalities and practices like commitment, satisfaction, and organizational citizenship behavior [4]. A few examinations have set up a promise to the central trade accomplice as a result of a social exchange relationship [42] [62] [65] [86]. Along these lines the rule variable, authoritative duty is grounded in the social exchange hypothesis. Through this applied paper we contend that workers who watch their organization be socially dependable create a more noteworthy duty to the organization and this responsibility capacities through sentiments of fulfillment.

The social identity theory recommends that individuals will in general classify themselves into a few social classifications [78]. Employees consider themselves to be having a place with a specific gathering or perceiving with the gathering [5]. The greater the peculiarity or unique nature of exercises of the gathering the more prominent is the identification [5]. Given this contention, we recommend that when representatives see the association to be socially capable, they will in general distinguish themselves more with the organization. This recognizable proof thus impacts their promise to the organization and this relationship works through their general feeling of fulfillment. Subsequently, the two factors can be associated through the bases of social exchange and social identity.

\section{LITERATURE REVIEW}

The term CSR has advanced dependent on the locale in which it was progressed and appears to have changed implications in various business settings. Consequently, the comprehension of this recognition is diffuse and loaded with contradiction. However extensively, CSR is comprehended as the social, environmental, and legal obligations of an organization [69].CSR has been perceived as the duty of an organization to practice business morally while adding to the employees, clients, nearby networks, and society [88]. The idea of CSR has been concentrated through the grounds of economics, sociology, strategy, management, and environmental studies, among others. Surviving writing 
draws on these fluctuated territories, hence raising comprehension of CSR yet also prompting different and diffuse translations. CSR has fluctuating implications including 'ethical behavior', 'responsible behavior', 'legitimate behavior' or simply fulfillment of 'fiduciary duty' [84]. The idea of CSR has been contended upon vigorously since the beginning of industrialization as the impact of business activities on society and condition accepted new measurements. Post-industrialization methods of reasoning about the social duty of organizations have developed into what we perceive as the present-day idea of CSR. The idea of CSR looks to some extent like a few different ideas like corporate citizenship [17], corporate social responsiveness [77], corporate social performance [87], and stakeholder management [36]. Interrelating organizational performance and progress of the community have been recommended as a " shared value " approach. Of every one of these terms, CSR is the most ordinarily utilized term and it alludes to the commitment that an organization has toward society [60].CSR noticed that the term alludes to the association's commitment to contemplate social factors notwithstanding financial and legitimate components while taking part in dynamic [24].CSR as far as the social obligation of the foundation, association, and individual along these lines, encompassing three levels [87].' Corporate citizenship included a connection between the association and society which incorporated the neighborhood network' [47].CSR has the four particular variables of the monetary, lawful, moral, and altruistic obligation of the business toward its partners [17]. Notwithstanding, it shows up reasonable for presume that there is no significant concession to what CSR includes and a solitary definition has not been settled upon.

There are in any case, some common components among all these various definitions and conceptualizations. To start with, there is a concession to the way that CSR exercises should be inside lawful limits [17] [67]. Thus, it is basic that organizations participate in exercises that agree by the traditions that must be adhered to on the off chance that they are to be perceived as socially capable associations. Second, all conceptualizations address the issue of duty toward partners, including the network and condition. In any case, the easily proven wrong issue is that various partners may have dissimilar requirements and it may be hard for an association to fulfill all these restricting needs. Thus, changing requests from various partners could prompt a wide scope of CSR exercises. Third, CSR constantly alludes to social responsiveness or positive activity of business while in transit to society. Subsequently, the principle point of CSR exercises ought to be the advantage of the general public. At long last, most specialists concur that CSR infers activity and thus can be operationalized regarding explicit activities of an organization toward being socially dependable, moral, and meeting lawful prerequisites.

CSR is dimensioned as far as a monetary obligation, lawful duty, moral obligation, and optional duty [18]. It is estimated through worker perceptions of organizational action on these four measurements [44]. A few examinations have inspected the connection between association morals and job satisfaction [39]. There is a connection between five elements of employee satisfaction and top administration's feeling of morals on a moral idealism scale, i.e., the level of good faith that one has concerning the positive connection among morals and accomplishment in his organization [82] [83]. They found a positive connection between job satisfaction and morale of good faith. All aspects of employment satisfaction aside from pay fulfillment were affected by apparent moral conduct of top administration. Research has additionally indicated that workers who are occupied with the social activities of the organization are progressively happy with their activity [37].

\section{JOB SATISFACTION}

Job Satisfaction is communicated as the degree to which a representative has a positive full of feeling direction or attitudinal response to the activity [72] [73]. It alludes to the influence-based responses of workers to highlights the activity like the activity itself, supervisor, and pay. Job Satisfaction alludes to a representative's general feeling of prosperity at work. It is an inner state dependent on assessing the activity and employment-related encounters with some level of favor or disapproval [43]. Job Satisfaction is found to positively affect execution and inspiration and a negative relationship with the turnover intention [76]. Job Satisfaction has been protected as both a worldwide idea alluding to in general satisfaction and as a feature explicit idea alluding to different parts of work, for example, pay, management, or outstanding task at hand [21]. On a more significant level, there happens a positive match between job satisfaction and high confidence, high self-adequacy, and low neuroticism [75]. The writing on the connection between job satisfaction and organizational commitment is separated from certain investigations implying that job satisfaction goes before commitment while most demonstrating that job satisfaction is a relationship of commitment [53].

\section{ORGANIZATIONAL COMMITMENT}

Organizational commitment was portrayed by the accompanying,

"strong faith in and acknowledgment of the authoritative goals and values ",

"willingness to apply extensive exertion for the organization", and 
" want to keep up authoritative participation." [61].

Comprehensively, authoritative responsibility expresses the employees' connection with their organization. Authoritative responsibility can be recognized from different types of commitment, as word related responsibility, pledge to the organization, commitment towards the objective and promise to the group or pioneer, established on the objective of duty. Research has to a great extent mindful of a pledge to the organization. Worker responsibility to the group or pioneer is regularly viewed as an enhancement of pledge to the organization [11]. Organization is typically is viewed as a 'monolithic, undifferentiated entity that elicits an identification and attachment on part of the individual', while as a general rule an individual could have fluctuating responsibility profiles. Organizational commitment is best comprehended as an assortment of various duties to explicit foci [63]. The worldwide organizational commitment had genuinely strong connections with job satisfaction, turnover plan, and organizational citizenship conduct, and augmentation in expectation contributed by a promise to explicit foci was very little [51]. Model of responsibility had been established in the work environment utilizing the definition that responsibility is a "settling power that ties an individual to a strategy" [52] [61]. Organizational commitment, thus, remains the idea from which a large portion of different models of working environment responsibility, except organization responsibility, has been set up [52].

Early writing had conceptualized organizational responsibility as a unidimensional worldview [12] [54] while later writing will in general view it as a multidimensional development [1] [3] [46] [58]. Organizational commitment states to the employee's emotional bond with the organization [54]. Resulting research on organizational commitment analyzed a few inspirational bases for organizational commitment. The commitment was affected by speculations and options, commitment through guidelines of correspondence, and distinguishing proof [66]. Three-segment conceptualization of organizational commitment (OC) was proposed viz., affective commitment (AC), normative commitment (NC), and continuance commitment (CC) which is the widely acknowledged conceptualization of organizational commitment [1].

\section{PROPOSITIONS}

Proposition 1: CSR activities will be positively related to job satisfaction.

Proposition 2: CSR activities will be positively correlated with employee's affective, normative, and continuance commitment.
Proposition 3: Job satisfaction will mediate the relationship between CSR activities and affective, normative, and continuance commitment.

CSR is dimensionalized regarding economic duty, legitimate obligation, moral duty, and discretionary duty [18]. It is estimated through worker perception of organizational activity on these four measurements [44]. For simplicity of understanding, we will call this composite variable as an impression of CSR. A few investigations have analyzed the connection between association morals and job satisfaction [39] [82]. There is a connection between five elements of job satisfaction and top administration's feeling of morals on a moral hopefulness scale, i.e., the level of good faith that one has concerning the positive connection among morals and achievement in his/her organization [83]. They found a positive connection between job satisfaction and morale hopefulness. All parts of job satisfaction except for pay satisfaction were affected by apparent moral conduct of top administration. Exploration has additionally indicated that representatives who are engaged with the social activities of the association are progressively happy with their job [37]. This implies a view of socially mindful conduct by the association positively affect job satisfaction, and it likewise puts a more noteworthy obligation on the association or its operators to carry on in a socially dependable way.

There is an association between organizational commitment and representative view of CSR dependent on the theoretical establishments of social identity theory [16]. The view of CSR was emphatically associated with worker commitment [16]. Apparent moral activity by an organization affects people who are surveying that specific association as a potential employer [32]. In light of the social identity theory, it was noticed that the view of socially capable conduct of the organization is probably going to grow more recognizable proof and inclusion with the organization. Affective commitment is conceptualized as far as recognizable proof and contribution with organizational exercises while normative commitment is a feeling of commitment toward the organization [48]. From the perspective on social identity, one can propose that workers will relate to the organization while the social exchange see contends for reimbursement of commitments in this manner made. Subsequently, it is recommended that workers who see that their organization to be socially mindful are probably going to react with more prominent affective and normative commitment.

The third part of the responsibility is continuance commitment, which is conceptualized as far as low alternatives and high sacrifices. Representatives who see that the organization is socially capable are bound to confide in the association and be focused on it. In any case, there appears to be no motivation to accept that 
representatives who are sincerely engaged with the organization want to legitimize their proceeded with nearness in the association inferable from reasons like absence of choices [57]. Truth be told, writing demonstrates a negative relationship between continuation commitment and the other two elements of commitment [53]. In any case, the Hi Sac (high sacrifices) segment of continuation commitment is found to act unexpectedly [49].

The connection between responsibility and organizational commitment is as yet a subject of discussion [41]. Analysts have discovered causal and correlational relationships [10] [45]. Job satisfaction is an associate of organizational commitment [53]. This paper perceives that the majority of the surviving literature places job satisfaction as a forerunner of organizational commitment [7] [8] [63]. Hypothetical and observational work suggests that representatives who are increasingly fulfilled will be progressively dedicated to the organization [10] [22]. Every part of commitment creates because of the assorted encounters of the person. Affective commitment alludes to a passionate connection and recognizable proof with the organization [1]. Social identity theory suggests that when an individual partners with an association that is seen to be socially mindful it prompts huge satisfaction [78]. We guarantee that this satisfaction thusly prompts identification and connection with the organization. Social exchange alludes to an exchange that happens attributable to the positive willful activity of one gathering toward another [13]. In the organizational setting, this is regularly translated as the optional positive activity of the association or its operators. People who feel obliged are probably going to respond with their dedication toward the organization. In India the idea of CSR draws profoundly on the thought of social trusteeship, i.e., CSR is a greater amount of corporate charity and positive activity coordinated toward the worker. In such settings, doubtlessly representatives who profit by positive organizational activity are bound to be fulfilled and this thusly prompts them to respond with their responsibility [38]. Subsequently, we recommend that job satisfaction is a presumable arbiter of the connection between CSR activities and organizational commitment.

\section{THE CONCEPTUAL MODEL}

The model, CSR activities, and Organizational Commitment is portrayed in Figure 1. From the first audit of writing and conversations, we have built up a model connecting CSR exercises with organizational commitment and employee job satisfaction to comprehend measurements of CSR influencing attitudinal factors like organizational commitment and employee satisfaction and consequently draw out a chance of associations having the option to sort CSR activities dependent on the stakeholders they impact.

In this model, we exhibit that even the impression of socially capable activities of the association adds to positive results like commitment and fulfillment. While perceived organizational support and equity recognitions are made if the representative is an immediate recipient of organizational activity, the view of CSR doesn't require the worker to be an immediate recipient. Truth be told, much of the time the representative is just an observer to the socially mindful demonstration of the association. This makes an open door for associations to 'oversee' attitudinal factors like commitment and satisfaction.

An organization can't meet the CSR desires for all stakeholder groups. Likewise, there are a few exercises, which lead an organization to be named socially mindful. Organizations have a decision of CSR activity dependent on stakeholder groups. Organizations, today are putting intensely in CSR activities with an assortment of destinations. Through this model, we plan to exhibit that managers may be decidedly disposed toward CSR activities inferable from a few organizationally valuable results. Be that as it may, the proposed model recommends that workers who see their association be socially capable react with more prominent commitment. This thusly has numerous positive results like improved efficiency, reduced turnover, and better execution. Organizations should incorporate social activities as a component of human resource practices and include their employees in these activities.

Figure No. 1: The role of job satisfaction in the connection between CSR activities and organizational commitment

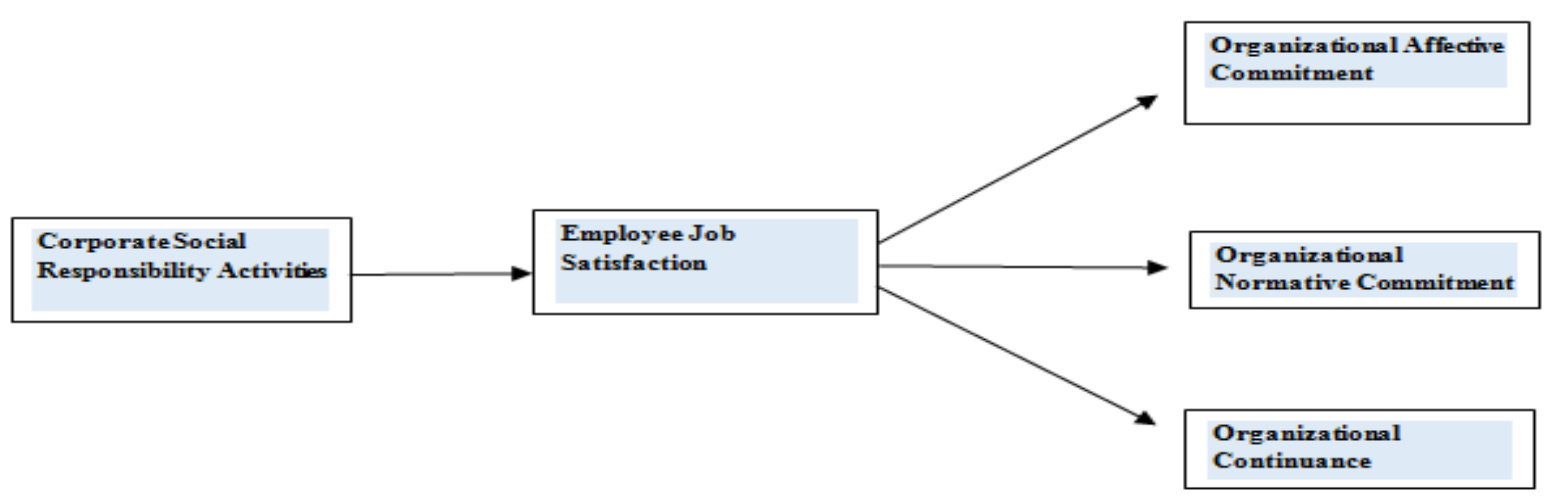




\section{IMPLICATIONS OF THE MODEL}

The significant ramifications of this model are that associations can shape a committed workforce through positive organization activity. Prior, positive organizational activity was arranged as far as perceived organizational support (POS) [57] or organizational equity [31]. Through this model, we show that socially dependable activities of the association add to positive results, for example, responsibility and satisfaction. While perceived organizational support (POS) and equity recognitions are framed if the representative is an immediate recipient of organizational activity, the view of CSR doesn't require the worker to be an immediate recipient. Actually, as a rule, the worker is just an observer of the socially dependable demonstration of the association. This makes an opportunity for the organization to 'oversee' attitudinal factors like commitment and satisfaction.

The different advantages of having a committed workforce and backhanded advantages of CSR are unmistakably noteworthy for an organization in the present quickly changing business condition. The model has huge ramifications for the CSR arrangements of organizations. An organization can't meet the CSR viewpoint of all partner gatherings. Likewise, there are a few activities, which lead an organization to be delegated socially dependable. Organizations have a choice of CSR activity dependent on partner gathering. Organizations, today are putting vigorously in CSR activities with various targets. Through this model, we would like to set up that employers may be emphatically disposed toward CSR activities attributable to a few authoritatively gainful outcomes. It is now and again felt that boost of investor riches is at the expense of partner satisfaction and henceforth social obligation and operational effectiveness are dissimilar requests on the organization. In any case, the proposed model recommends that workers who see their organization be socially mindful react with more prominent responsibility. This thusly has different positive results like upgraded profitability, diminished turnover, and better execution. It is henceforth, proposed that organizations ought to incorporate social activities as a major aspect of the human asset rehearses and draw in their representatives in these activities.

\section{CONCLUSION AND FUTURE RESEARCH DIRECTIONS}

Job satisfaction is found to have a positive impact on performance and motivation and a negative correlation with the turnover intention [76]. Corporate Social Responsibility activities are positively related to job satisfaction. Multiple-constituency framework was tested and found that global organizational commitment had fairly strong correlations with job satisfaction, turnover intent, and organizational citizenship behavior and increment in prediction contributed by a commitment to specific foci was quite small [51]. A generalized model of commitment in the workplace had been developed using the definition that commitment is a "stabilizing force that binds a person to a course of action" [52] [61]. A threecomponent conceptualization of organizational commitment viz., affective commitment, normative commitment, and continuance commitment which is the most widely accepted conceptualization of organizational commitment. CSR activities are positively correlated with employee's affective, normative, and continuance commitment [1].

Hence, based on social exchange and social identity perspectives, that perceptions of CSR have a positive influence on the commitment of employees and this relationship will be mediated by the job satisfaction of the employees. Job satisfaction mediates the relationship between CSR activities and affective, normative, and continuance commitment.

Exact help for the model is important to inspect whether the view of CSR has any effect on representative duty far beyond worker commitment practices. The Indian economy has been developing every year and is among the quickest developing economies on the earth. This development joins a strong need to increase the executive's rehearsed that are representative well-disposed and empower organizations to stay serious through its workers. As the following stage, we suggest that the model be tried with regards to the Indian pharmaceutical industry. The business is experiencing change and in conditions, for example, worldwide pandemic COVID-19, it is imperative to cultivate committed employees as a wellspring of the continued upper hand. The model proposed will be tried through structural equation modeling (SEM), as it indicates the nearness of the intercession for both first and second-order latent constructs.

The fundamental target of the paper is to extend the current assemblage of information on organizational commitment. Writing has discovered a negative relationship between dedication and intention to quit [53]. Henceforth, the model is appropriate to all ventures that face high attrition. We suggest that while it is helpful to connect with the worker through positive HR practices, it is much increasingly critical to include in socially capable conduct since this manages an organization the twofold advantage of representative inclusion and fringe picture building.

\section{REFERENCES}

[1] Allen NJ, Meyer JP. (1990). The measurement and antecedents of affective, continuance, and normative commitment. Journal of Occupational Psychology, 63:1-18.

[2] Allen DG, Shore LM, Griffeth RW. 2003. The role of perceived organizational support and supportive human 
resource practices in the turnover process. Journal of Management, 29(1):99-118.

[3] Angle HL, Perry JL. 1981. An empirical assessment of organizational commitment and organizational effectiveness. Administrative Science Quarterly 27:1-14.

[4] Aryee S, Budhwar PS, Xiong Chen Z. 2002. Trust as a mediator of the relationship between organizational justice and work outcomes: Test of a social exchange model. Journal of Organizational Behavior, 23:267-285.

[5] Ashforth BE, F Mael. 1989. Social identity theory and the organization. Academy of Management Review, 14(1):20-39.

[6] Aupperle KE, Carroll AB, Hartfield JD. 1985. An empirical examination between corporate social responsibility and profitability. Academy of Management Journal, 28(2):446463.

[7] Bagozzi RP. 1992. The self-regulation of attitudes, intentions and behavior. Social Psychology Quarterly, 55(2):178-204.

[8] Bartol KM. 1979. Professionalism as a predictor of organizational commitment, role stress and Turnover: A multidimensional approach. Academy of Management Journal, 22:815-821.

[9] Barney J. 1991. Firm resources and sustained competitive advantage. Journal of Management, 17(1):99- 120.

[10] Bateman TS, Strausser S. 1984. A longitudinal analysis of the antecedents of organizational Commitment. Academy of Management Review, 27:95-112.

[11] Becker TE. 1992. Foci and bases of commitment: Are they distinctions worth making. Academy of Management Journal, 35(1):232-24.

[12] Blau GJ. 1985. The measurement and prediction of career commitment. Journal of Occupational Psychology, 58: 277288 .

[13] Blau P. 1964. Exchange and power in social life. Wiley: New York.

[14] Blegen M. 1993. Nurses' job satisfaction: A meta-analysis of related variables. Nursing Research, 42(1): 36-41.

[15] Boyacigiller NA, Adler N J. 1991. The parochial dinosaur: Organizational science in a global context. Academy of Management Review, 16(2):262-290

[16] Brammer S. Millington A, Rayton B. 2007. The contribution of corporate social responsibility to organizational commitment. International Journal of Human Resource Management, 18(10):1701-1719.

[17] Carroll AB. 1979. A three-dimensional conceptual model of corporate performance. Academy of Management Review, 4(4): 497-505

[18] Carroll AB. 1991. The pyramid of corporate social responsibility: Towards the moral management of organizational stakeholders. Business Horizons, JulyAugust:39-48.

[19] Cellucci AJ, DeVries DL. 1978. Measuring managerial satisfaction : A manual for the MJSQ, Technical report II (Center for Creative Leadership).

[20] Cobb AT, Wooten KC, Folger R. 1995. Justice in the making: Toward understanding the theory and practice of justice in organizational change and development. Research in Organizational Change and Development, 8: 243-295.
[21] Cook JD, Hepworth SJ, Wall TD, Warr PB. 1983. The experience of work: A compendium and review of 249 measures and their use, Academic Press: New York.

[22] Currivan DB. 1999. The causal order of job satisfaction and organizational commitment in models of employee turnover. Human Resource Management Review, 9(4): 495-524.

[23] Dansereau F, Graen G, Haga WG. 1975. A vertical dyad linkage approach to leadership within formal organizations: A longitudinal investigation of the role making process. Organizational Behavior and Human Performance, 13: 46-78.

[24] Davis K. 1973. The case for and against business assumption of social responsibilities. Academy of Management Journal, 16(3): 312-322.

[25] Deshpande SP. 1996. The impact of ethical climate types on facets of job satisfaction: An empirical investigation. Journal of Business Ethics, 15: 655-660.

[26] Downes M, Hemmasi M, Graf L, Kelley L \& Huff L. 2002. The propensity to trust: A comparative study of United States and Japanese managers. International Journal of Management, 19(4): 614-621.

[27] Earley PC, Gibson CB. 1998. Taking stock in our progress on individualism-collectivism: 100 years of solidarity and community. Journal of Management, 24: 265-304.

[28] Eisenberger R, Cotterell N, Marvel J. 1987. Reciprocation ideology. Journal of Personality \& Social Psychology, 53:743-750.

[29] Eisenberger R, Huntington R. Hutchison S, Sowa D. 1986. Perceived organizational support. Journal of Applied Psychology, 75: 51-59.

[30] Epitropaki O. 2003. Transformational leadership, psychological contract breach and organizational identification. Academy of Management Best Paper Proceedings OB: M1-M6.

[31] Folger R, Konovsky M. 1989. Effects of procedural and distributive justice on reactions to pay raise decisions. Academy of Management Journal, 32(1): 115-130.

[32] Greening DW, Turban DB. 2000. Corporate social responsibility as a competitive advantage in attracting a quality workforce. Business and Society, 39: 254-280.

[33] Greenfield WM. 2004. In the name of corporate social responsibility. Business Horizons47(1): 19-28.

[34] Irvine DM, Evans MG. 1995. Job satisfaction and turnover among nurses: Integrating research across studies. Nursing Research, 44(4): 246-253.

[35] Johnson JJ, McIntyre CL. 1998. Organizational culture and climate correlates of job Satisfaction. Psychological Research, 82: 843-850.

[36] Jones TM 1995. Instrumental stakeholder theory: A synthesis of ethics and economics. Academy of Management Review, 20(2): 404-437.

[37] Jurkiewicz CL, Massey Jr. TK. 1997. What motivates municipal employees: A comparison study of supervisory vs. non-supervisory personnel. Public Personnel Management, 26(3): 367-377

[38] Khan S. 2008. Corporate social responsibility from an emerging market perspective: Evidences from the Indian pharmaceutical industry. Unpublished doctoral dissertation University of St. Gallen, Bamberg. 
[39] Koh HC, Boo EHY 2001. The link between organization ethics and job satisfaction: A study of managers in Singapore. Journal of Business Ethics, 29: 309-324.

[40] Konovsky M, Pugh S. 1994. Citizenship behavior and social exchange. Academy of Management Journal, 37: 656-669.

[41] Koslowsky M, Caspy T, Lazar M. 1991. Cause and effect explanations of job satisfaction and commitment: The case of exchange commitment. Journal of Psychology, 125(2):153162.

[42] Liden RC, Wayne SJ, Kraimer ML, Sparrowe RT. 2003. The dual commitments of contingent workers: An examination contingents' commitment to the agency and organization. Journal of Organizational Behavior, 24(5): 609-625.

[43] Locke E A. 1976. The nature and causes of job satisfaction. In Handbook of I/O Psychology, M. D. Dunnette (Ed).: RandMcNally: Chicago.

[44] Maignan I. Ferrell OC, Hult T. 1999. Corporate citizenship: Cultural antecedents and business benefits. Journal of the Academy of Marketing Science, 27(4): 455-469.

[45] Mathieu J, Zajac E. 1990. A review and meta-analysis of antecedents, correlates and consequences of organizational commitment. Psychological Bulletin, 108: 171-194.

[46] Mayer RC, Schoorman FD. 1992. Predicting participation and production outcomes through a two-dimensional model of organizational commitment. Academy of Management Journal, 35:671 - 684

[47] McIntosh M, Leipziger D, Jones K, Coleman G. 1998 Corporate citizenship: Successful strategies for responsible companies. Pitman Publishing: London.

[48] Meyer JP, Allen N. 1991. A three-component conceptualization of organizational Commitment. Human Resource Management Review, 1:61-98.

[49] McGee GW, Ford RC. 1987, Two (or more?) dimensions of organizational commitment: Reexamination of the affective and continuance scale. Journal of Applied Psychology, 72: $638-642$

[50] Meyer JP, Allen N, Smith C. 1993. Commitment to organizations and occupations: Extension and test of a threecomponent conceptualization. Journal of Applied Psychology, 78:538-551.

[51] Meyer JP. Allen NJ. 1997. Commitment in the workplace: Theory, Research and Application. Thousand Oaks: London.

[52] Meyer JP, Herscovitch L. 2001. Commitment in the workplace: Towards a general model. Human Resource Management Review, 11: 299-326.

[53] Meyer JP, Stanley DJ, Herscovitch L, Topolnytsky L. 2002. Affective, continuance, and normative commitment to the organization: A meta-analysis of antecedents, correlates and consequences. Journal of Vocational Behavior, 61: 20-52.

[54] Mowday RT, Porter LW, Steers RM. 1982. Employeeorganizational linkages: The psychology of commitment, absenteeism, and turnover. Academic Press: New York.

[55] Nambudiri R. 2012. Propensity to trust and organizational commitment: A study in the Indian pharmaceutical sector, The International Journal of Human Resource Management, 23(5): 977-986.

[56] Obrad, C. \& Gherheş, V. 2018. A human resources perspective on responsible corporate behavior. Case study: the multinational companies in Western Romania. Sustainability, 10(726):1-15.
[57] O’Driscoll MP, Randall DM. 1999. Perceived organizational support, satisfaction with rewards and employee jobinvolvement and organizational commitment. Applied Psychology, 48: 197-209.

[58] O'Reilly CA, Chatman J. 1986.Organizational commitment and psychological attachment: the effects of compliance, identification, and internalization on prosocial behavior. Journal of Applied Psychology, 71: 492-499.

[59] Ostroff C. 1993. The effects of climate and personal influences on individual behavior and attitudes in organizations. Organization Behavior and Human Decision Processes, 56: 56-90.

[60] Porter ME, Kramer MR. 2011. Creating shared value, Harvard Business Review, January-February: 62-77.

[61] Porter LW, Steers R, Mowday R, Boulian PV. 1974 Organizational commitment, job satisfaction and turnover among psychiatric technicians. Journal of Applied Psychology, 59: 603-609.

[62] Redman T, Snape E. 2005. Unpacking commitment: Multiple loyalties and employee behavior. Journal of Management Studies, 42(2): 301-328.

[63] Reichers AE. 1985. A review and reconceptualization of organizational commitment. Academy of Management Review, 10(3): 465-476.

[64] Rhoades L, Eisenberger R, Armeli S. 2001. Affective commitment to the organization: The contribution of perceived organizational support. Journal of Applied Psychology, 86: 825-836.

[65] Saavedra R, Van Dyne L. 1999. Social exchange and emotional investment in work groups. Motivation and Emotion, 23(2): 105-124.

[66] Scholl RW. 1981. Differentiating organizational commitment from expectancy as a motivating force. Academy of Management Review, 6(4): 589-599.

[67] Sethi SP. 1979. A conceptual framework for environmental analysis of social issues and evaluation of business response pattern. Academy of Management Review, 4(1): 63-74.

[68] Settoon RP, Bennett N, Liden NC. 1996. Social exchange in organizations: Perceived organizational support, leadermember exchange and employees' reciprocity. Journal of Applied Psychology, 81: 219-227.

[69] Shamir R. 2005. Mind and Gap: The commodification of corporate social responsibility Symbolic Interaction, 20: 229253.

[70] Shore LM, Wayne SJ. 1993. Commitment and employee behavior: Comparison of affective commitment and continuance commitment with perceived organizational support. Journal of Applied Psychology, 78: 774-780.

[71] Sinclair A.1993. Approaches to organization culture and ethics. Journal of Business Ethics, 12: 63-67.

[72] Smith PC, Kendall LM, Hulin CL. 1969. The measurement of satisfaction in Work and Retirement: A Strategy for the Study of Attitudes. Rand McNally \& Co: Chicago.

[73] Spector PE. 1985. Measurement of human service staff satisfaction: Development of the Job Satisfaction Survey. American Journal of Community Psychology, 13(6): 693-713.

[74] Spence-Laschinger HK, Finegan JE. 2004. Empowerment, interactional justice, trust and respect: A nursing recruitment and retention strategy. Academy of Management proceedings. 
[75] Srivastava A, Locke EA. 2006. Dispositional Causes of Job Satisfaction: Seeking complexity in job as a mediator. Academy of Management Best Paper Proceedings.

[76] Stazyk EC. 2010. Public service motivation and job satisfaction: The role of fit and mission valance. Academy of Management Annual meeting proceedings, 1-6.

[77] Strand R. 1983. A system paradigm of organizational adaptations to the social environment. Academy of Management Review, 8(1): 90-96.

[78] Tajfel H, Turner JC. 1986. The social identity theory of intergroup behavior. In Psychology of Intergroup Relations. Austin S and Austin WG (Eds) NelsonHall: Chicago IL.

[79] Tewari, R. \&Nambudiri R. Perceived CSR, Organizational Commitment and Job Satisfaction: A conceptual model.

[80] Tsai MT, Huang CC. 2008. The relationship between ethical climate types and facets of job satisfaction, and the three components of organizational commitment: A study of nurses in Taiwan. Journal of Business Ethics, 80:565-581.

[81] Ullmann AA. 1985. Data in search of a theory: A critical examination of the relationships among social performance, social disclosure, and economic performance of U.S. firms. Academy of Management Review, 10(3):540-557.

[82] Viswesaran C, Deshpande SP. 1996. Ethics, success and job satisfaction: A test of dissonance theory in India. Journal of Business Ethics, 15:1065-1069.

[83] Vitell SJ, Davis DL. 1990. The relationship between ethics and job satisfaction: An empirical investigation. Journal of Business Ethics, 9:489-494.

[84] Votaw D. 1973. 'Genius Becomes Rare', in The Corporate Dilemma: Traditional Values versus Contemporary Problems. D Votaw and SP Sethi (eds). Prentice-Hall: Englewood Cliffs, NJ.

[85] Wayne SJ, Shore LM, Liden RC. 1997. Perceived organizational support and leader-member exchange: A social exchange perspective. Academy of Management Journal, 40: $82-111$.

[86] Whitener EM. 2001. Do high-commitment human resource practices affect employee commitment? A cross-level analysis using hierarchical linear modeling. Journal of Management, 27: $515-535$

[87] Wood D. 1991. Corporate social performance revisited. Academy of Management Review, 16(4): 691-718.

[88] Wright M. 1999. Corporate Social Responsibility: Making Good Business Sense. World Business Council for Sustainable Development proceedings.

[89] Yapar, A. 2017. The Effect of Corporate Social Responsibility on Employee Satisfaction and Loyalty: A research on Turkish Employees. International Research Journal of Interdisciplinary \& Multidisciplinary Studies, 3(1):87-105.

[90] Shuli, G. and Suwandee, S. 2017. Effect of corporate social responsibility on employee job performance: A case study of household products manufacturers in southern China. Journal of Thai Interdisciplinary Research, 12 (5): 57 - 63.

[91] Shareef, V. A., Husien, A. H., and Omer, S. K. 2018.The effect of Interior design on employees job satisfaction. Journal of Process Management - New Technologies, International, 6(2). 